Published online: November 10, 2010

\title{
Prostate Cancer Masquerading as a Rectal Tumor: A Tricky Diagnosis
}

\author{
Rebecca A. Levine Stephen Priest \\ Department of Colon and Rectal Surgery, William Beaumont Hospital, Royal Oak, Mich., USA
}

A 59-year-old man presented with diarrhea, abdominal cramps, tenesmus, and a 13.5-kg weight loss over 1 month. Rectal examination revealed a fixed and nodular, lowlying anterior mass. Sigmoidoscopy confirmed a malignant-appearing tumor, approximately $18 \mathrm{~cm}$ long, with severe luminal narrowing and diffuse mucosal involvement (fig. 1). CT scan also demonstrated this obstructing mass (fig. 2), with associated lymphadenopathy and free fluid. CEA level was normal but PSA proved markedly elevated $(358.7 \mathrm{ng} / \mathrm{ml})$. Biopsies confirmed prostate adenocarcinoma with full-thickness rectal wall invasion. The patient was treated with diversion and leuprolide, and is doing well at 4 months with a PSA of $3.3 \mathrm{ng} / \mathrm{ml}$.

Prostate cancer rarely infiltrates the rectum despite the close proximity of these two organs. The low frequency of this (only up to $9 \%$ in autopsy studies) has been attributed to the protective barrier of Denonvilliers' fascia [1]. Full-

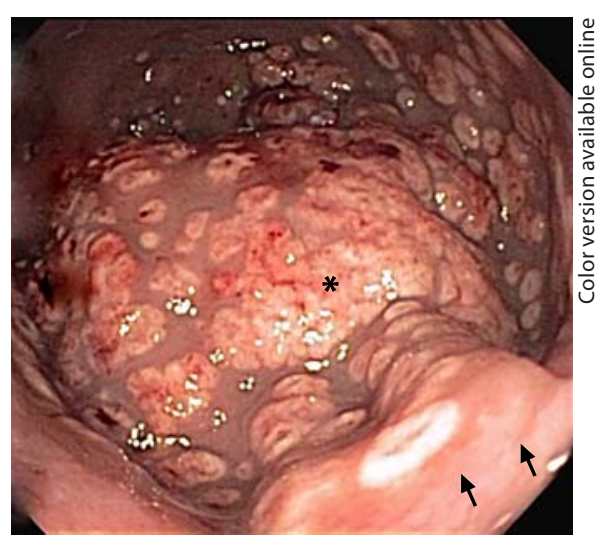

Fig. 1. Flexible sigmoidoscopy demonstrates a fixed, irregular rectal mass associated with severe luminal stenosis and diffuse mucosal deposits (asterisk) extending to the dentate line (arrows). thickness penetration involving the rectal mucosa, as seen in this patient, is even more unusual but critical to recognize as these findings on endoscopy and CT can easily be mistaken for a primary rectal carcinoma [2]. Given that treatment of these two entities is completely different, a high index of suspicion and histologic confirmation are essential in order to avoid inappropriate radical resection.

\section{Disclosure Statement}

The authors have no conflict of interest.

\section{References}

1 Bowrey DJ, Otter MI, Billings PJ: Rectal infiltration by prostatic adenocarcinoma: report on six patients and review of the literature. Ann R Coll Surg Engl 2003;85:382-385.

$\checkmark 2$ Guo CC, Pisters LL, Troncoso P: Prostate cancer invading the rectum: a clinicopathological study of 18 cases. Pathology 2009;41:539-543.

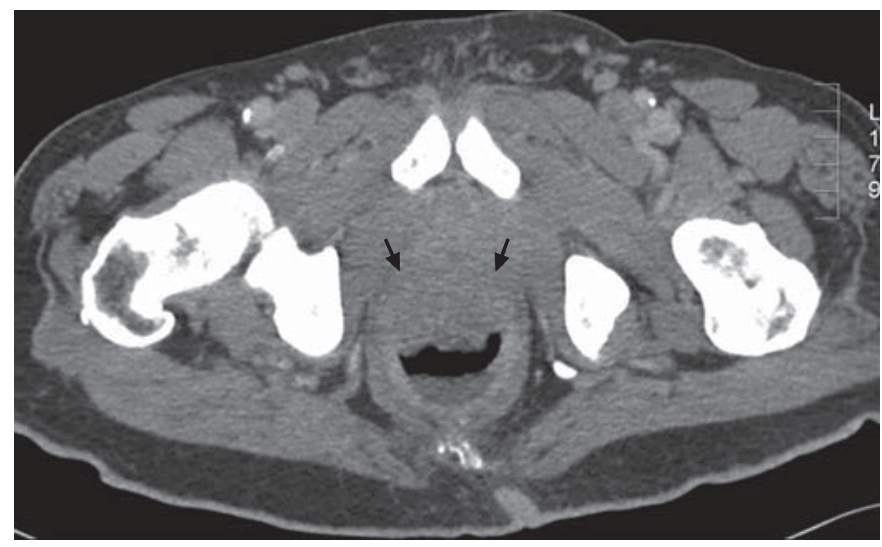

Fig. 2. CT scan of the pelvis shows an anterior mass in the distal rectum causing luminal compression with adjacent lymphadenopathy and free fluid suspicious for a neoplasm (arrows).

\section{KARGER}

Fax +41613061234 E-Mail karger@karger.ch www.karger.com (c) 2010 S. Karger AG, Basel

0253-4886/10/0276-0466\$26.00/0

Accessible online at:

www.karger.com/dsu
Rebecca A. Levine, MD

Department of Colon and Rectal Surgery, William Beaumont Hospital 4002 West 13 Mile Rd No. 28

Royal Oak, MI 48073 (USA)

Tel. +1 347351 7439, Fax +1 248541 1791, E-Mail rebecca.levine@ mssm.edu 